\title{
Dialogue in mathematics classrooms: beyond question-and- answer methods
}

\author{
Karin Brodie \\ School of Education, Wits University \\ Email: karin.brodie@wits.ac.za
}

\begin{abstract}
This paper explores different kinds of interaction observed in South African mathematics classrooms in order to unpack the notion of participation in mathematics learning. It argues that conventional questionand-answer methods do not promote the kind of interaction that the new South African curriculum calls for. It presents more appropriate kinds of interactions, where teachers maintain high task demands, respond to genuine learner questions and support conversations among learners. The paper argues that combinations of different kinds of interaction are most likely to support learner participation and mathematical thinking in classrooms.
\end{abstract}

\section{Introduction}

The new curriculum in South African schools calls for learners to participate in mathematics lessons and to express their mathematical ideas. Learner talk is seen to be important because it (i) shows that learners are attending to the lesson; (ii) allows learners to express and clarify their own ideas; (iii) enables learners to share ideas with each other; and (iv) provides teachers with information about what learners know and don't know, and how learners are thinking and trying to make sense of ideas. Teachers are encouraged to make their lessons more learner-centred by encouraging learners to contribute to the lesson.

However, teachers are given very little guidance as to what such participation actually might look like. The new curriculum encourages teachers to be facilitators, although what this means, beyond "not telling" (Chazan \& Ball, 1999), is not often elaborated (see Brodie, 2003, for some ideas on this). Many teachers believe that if they ask questions and learners provide answers, learners are participating in the lesson. However classroom research has identified a number of different interaction patterns, which, to varying degrees, are supportive of genuine mathematical thinking. This research shows that many questionand-answer exchanges are not helpful in developing learners' mathematical thinking. Drawing on this literature and on research with grade 10 and 11 mathematics teachers in Johannesburg, I identify a number of different kinds of classroom dialogue. I show that there is a range of possibilities for learner-centred interaction in mathematics classrooms, which take us beyond the idea that teachers can encourage genuine dialogue and learner participation merely by asking questions.

\section{Classroom discourse}

About 30 years ago Sinclair and Coulthard (1975) and Mehan (1979) identified a key structure of classroom discourse, the Initiation-ResponseFeedback/Evaluation (IRF/E) exchange structure. The teacher makes an initiation move, a learner responds, the teacher provides feedback or evaluates the learner response and then moves on to a new initiation. Mehan calls this basic structure a sequence. Often, the feedback/evaluation and subsequent initiation moves are combined into one turn, and sometimes the feedback/evaluation is absent or implicit. This gives rise to an extended sequence of initiation-response pairs, where the repeated initiation works to achieve the response the teacher is looking for. When this response is achieved, the teacher positively evaluates the response and the extended sequence ends.

Neither Sinclair and Coulthard (1975) nor Mehan (1979) evaluated the consequences of the IRF/E structure. Other researchers (Edwards \& Mercer, 1987; Nystrand, Gamoran, Kachur \& Prendergast, 1997; Wells, 1999) have argued that it may have both positive and negative consequences for learning. Although this structure requires a learner contribution at every other turn (the response move), and therefore apparently gives learners time to talk, much research has shown that because teachers tend to ask questions to which they already know the answers (Edwards \& Mercer, 1987) and to 'funnel' learners' responses toward the answers that they want (Bauersfeld, 1980), space for genuine learner contributions is limited. For this reason, some researchers suggest 
that a complete shift of the IRE structure is necessary to achieve the goals of learner engagement and inquiry. Classroom discussions should become more like conversations, with the teacher being a participant in similar ways to the learners (Davis, 1997). However, there are enormous challenges involved in creating conversations in classrooms (Brodie, 2007) and it can be difficult for teachers to move away from the IRE exchange structure (Wells, 1999). So, in trying to understand different possibilities for interaction, it is important to try to understand the benefits that the IRE can afford. Whether the IRE has positive or negative consequences for learning will most likely depend on the nature of the elicitation and evaluation moves, which in turn influence the depth and extent of learners' responses.

Initiation moves are often in the form of questions, and a number of researchers have focused on teacher questions. Nystrand et al. (1997) distinguish between "test" questions and "authentic" questions. "Test" questions aim to find out what learners know, and how closely their responses correspond to what the teacher requires. "Authentic" questions on, the other hand, are questions which do not have pre-specified answers, which convey the teacher's interest in what learners think, and which serve to validate learner ideas and bring them into the lesson. Researchers in mathematics classrooms have identified a broader range of questions.

Hiebert and Wearne (1993) have four categories: recall; describe strategy; generate problem; and explain underlying features. Boaler and Brodie (2004) have nine categories which include: getting information; probing; exploring concepts and relationships; and generating discussions. Both these studies compare teachers using traditional and new curriculum materials in the United States and show that although the teachers using new curriculum materials ask a significant number of questions that require information and recall, they also ask a broader range of questions than teachers using traditional curriculum materials, and they ask more questions that require conceptual engagement from learners. While some of these questions may or may not be authentic, questions that require learners to explore meaning and relationships help distinguish between different kinds of teaching, and have positive influences on learning (Boaler \& Brodie, 2004; Hiebert \& Wearne, 1993).

At the level of the feedback or evaluation move, researchers have shown that teachers often begin with more exploratory, higher-order questions and tasks, but that teacher and learners often collude to reduce the demands of the task, asking narrower questions (Stein, Grover \& Henningsen, 1996) and funnelling towards answers (Bauersfeld, 1980). Nystrand et al. (1997) distinguish high-level evaluations from the more conventional evaluations of the IRE structure. High-level evaluations endorse the importance, rather than the correctness, of a learner's response, and allow the contribution to modify or affect the course of the discussion in some way (Nystrand \& Gamoran, 1991). Nystrand and Gamoran also develop the notion of uptake, which they describe as follows: many of the teacher's questions are partly shaped by what immediately precedes them; the teacher takes the learners' ideas seriously, and encourages and builds on them in subsequent discussion; the teacher's next question is contingent on the learner's idea, rather than predetermined; the teacher picks up on learner ideas, "weaving them into the fabric of an unfolding exchange"; and the learner's ideas can change the course of the discussion.

Drawing on the above literature, I identify three different kinds of interaction that I observed in South African mathematics classrooms and I argue that each of these kinds of interaction can create genuine dialogue through genuine learner participation and teacher responsiveness. I begin by giving an example of the traditional questionand-answer method, and demonstrate how it might inhibit learner participation and thinking.

\section{Example 1: Questions and answers}

One of the main reasons why teacher questions are considered insufficient to ensure genuine participation and mathematical thinking is that teachers often ask very low-level questions (Boaler \& Brodie, 2004; Hiebert \& Wearne, 1993; Jina, 2007) and they ask questions to which they already know the answers (Edwards \& Mercer, 1987; Nystrand \& Gamoran, 1991). Edwards and Mercer show that curricula that encourage learner-centred teaching can put teachers in a double-binding situation, if teachers interpret such an approach as requiring them to get the required knowledge from learners. In this situation, teachers are in the unenviable position of having to ask questions of learners to get particular knowledge from learners into the public domain. If one learner doesn't know a particular answer, teachers then ask other learners, in the hope that someone will provide the expected response (Edwards \& Mercer, 1987; Lobato, Clarke, \& Ellis, 2005). Teachers continue to ask questions, progressively narrowing their questions 


\section{Karin Brodie}

until such a simple question is asked that a learner can provide it. This is the process identified as 'funnelling' by Bauersfeld (1980).

The following extract from a grade 11 classroom gives an example of funnelling. The class was working on the question: what changes and what stays the same when the graph of $y=x^{2}$ shifts 4 units to the left and becomes $y=(x+4)^{2}$. One learner claimed that the axes of symmetry of the two graphs are different and the teacher asked him why they are different. The learner answered that it is because the equations are different and the following exchange ensued:

27 Reagile $^{1}$ : The equations are different.

28 Teacher: The equations are different?

29 Reagile: (nods head)

30 Teacher: The equations are different? As long as you can have a difference in the equations, then they differ?

31 Reagile: I think so.

32 Teacher: Okay, let's say we have something like y equals... one was $\mathrm{x}$ plus four squared, what if we have another one, $\mathrm{y}$ equals minus $\mathrm{x}$ plus four squared [writes $y=(x+4)^{2}$, and $y=-(x+4)^{2}$ on board]. Are these equations the same or different?

33 Learners: They are the same.

34 Teacher: They are the same?

35 Reagile: Ee [yes] the value of ' $a$ ', whether it's negative or positive determines the shape of the graph (indicating with his hand).

36 Teacher: The value of?

37 Reagile: ' $a$ ' determines... okay, the value of ' $a$ ' determines the shape of the graph, so... (inaudible, indicating with his hand)

38 Teacher: So the value of ' $a$ ' determines the shape of the graph.

39 Reagile: Yes.

40 Teacher: So, but are you saying the equations are the same?

41 Reagile: (thinks, looks uncertain) Yes.

42 Teacher: They are the same, if you say they are the same, you simply mean when we substitute our values of $\mathrm{x}$ here and here, if we say $\mathrm{x}$ is two here and here (points to the two equations on the board) and you simplify, you will come to the same expression, when we simplify. Is that what you are saying?

\footnotetext{
${ }^{1}$ All learner names are pseudonyms.
}

43 Reagile: (inaudible)

44 Teacher: Okay, lets look at two and negative two (writes 2 and -2 on the board), are they the same?

45 Reagile: No.

46 Teacher: Why no?

47 Reagile: The other one is negative. (inaudible).

48 Teacher: The other one is negative, the other one is positive. What about those equations?

In this exchange the teacher challenged the learner's argument that because the equations are different, the axes of symmetry will be different. From the exchange it is evident that the teacher wanted the learners to think beyond the particular case that they were dealing with $\left[y=x^{2}\right.$ and $\left.y=(x+4)^{2}\right]$, where the equations are different, and to think about whether different equations always produce different axes of symmetry. The teacher's question about the two equations, $y=(x+4)^{2}$ and $y=-(x+4)^{2}$ is a case of the teacher raising the task demands, rather than lowering them (Stein, Smith, Henningsen, \& Silver, 2000). However, the teacher was so intent on getting the learners to see that different equations do not necessarily generate different axes of symmetry that he ignored Reagile's thinking and narrowed his own questions.

Some of the teacher's questions indicate that he does not agree with the learner (and hence the learner is probably wrong). For example in lines 28 and 30 , the teacher repeated the learner's response as a question "the equations are different?" with a tone that suggested disagreement. Similarly in lines 34 and 40, the teacher indicated disagreement that the equations on the board are the same. These are examples of a teacher asking questions to which he already knows the answers (Edwards \& Mercer, 1987; Nystrand \& Gamoran, 1991), and that when teachers repeat questions it usually means that the previous responses were incorrect and the teacher is looking for a different answer (Edwards \& Mercer, 1987).

An analysis of Reagile's claims in the above exchange suggests that he was arguing that the two equations essentially are the same, especially when you consider the axis of symmetry. The only difference in the two equations is the a-value, which determines the shape of the graph rather than the axis of symmetry. Reagile made this argument even in the face of the teacher's disagreement, suggesting that he was convinced of his position. Although the teacher listened to Reagile and repeated his contribution in line 38, he 
did not see it as a contribution to the more general question about differences in the axes of symmetry and so he ignored the gist of Reagile's argument. As the exchange progressed, the teacher narrowed his questions in a number of ways. By focusing attention on the features of the two equations, $y=(x+4)^{2}$ and $y=-(x+4)^{2}$, he removed attention from their relationship to the graphs, a move that Reagile resisted by continuing to focus on the relationships between the equation and the graph.

The teacher then went further by saying that they should merely consider substituting numbers into the equations. Finally, he narrowed the question to whether 2 and -2 are the same or different, a question that is obvious to any grade 11 learner, and that is so simple that it completely lost its relevance and context in relation to the original task. In the exchange Reagile was reduced to answering a simple question, rather than having his genuine mathematical thinking taken seriously.

The above is an exchange between a very good teacher and a very strong learner that went somewhat wrong. In this exchange the teacher tried to raise the level of the task, requiring more generalization. He had the knowledge to do so and was able to put up the two equations $\mathrm{y}=(\mathrm{x}+4)^{2}$ and $y=-(x+4)^{2}$ very quickly as an example of his own thinking. In reflecting on the incident, the teacher said that he was shocked by Reagile's apparent misconception, given Reagile's strength in mathematics, which might have been a reason for his narrowing of the questions. The fact that Reagile was able to articulate an argument and maintain a different position from the teacher, suggests that there is space for thinking in this class. However, in this case, the teacher was listening evaluatively and looking for a particular answer (Davis, 1997), which prevented him from seeing the strengths of the learner's thinking. The teacher eventually narrowed the task completely. The fact that even very good teachers can end up funnelling exchanges and narrowing the task suggests that examples and models of how to avoid this situation might be helpful. In the rest of this paper, I give three such examples.

\section{Example 2: Reversing the IRE}

This example comes from a grade 11 lesson in which learners asked a number of questions and the teacher responded to them. In an extended exchange of about 120 turns there were 15 learner questions, averaging 1 learner question every 8 turns for about a quarter of the lesson. This is unusual, since in many classrooms learners do not ask questions regularly. Extended learner questioning created a situation where the teacher was responding much of the time to learner ideas and he strategically used his responses to make teaching points. Viewing the video footage of the whole sequence gives a sense of a different kind of classroom, one that is more learner-directed because learners actually initiate many of the ideas. Space limitations do not allow me to show the whole sequence but I will try to convey some of the atmosphere of the dialogue by analysing a short part of the exchange here.

The lesson concerned the theorem, 'the angle subtended at the centre of a circle is twice the angle subtended at the circumference'. The learners had drawn a number of circles with angles at the centre and circumference subtended by the same arc, measured the angles and seen the relationship empirically. The teacher pushed them to articulate the relationship in appropriate mathematical terminology and they struggled, particularly with the word 'subtend' and with the concept that the two angles, one at the centre and one at the circumference, were subtended by the same arc. When learners could refer to particular angles by name, they could articulate the theorem, however when pushed by the teacher to articulate it more generally, without naming angles, learners struggled. The teacher spent about half the lesson on this issue, working with the IRE structure, pushing learners to articulate the theorem more appropriately.

In the second part of the lesson, the teacher asked a learner to put up a diagram she had drawn where a diameter subtended a ninety-degree angle at the circumference. This allowed the teacher to help the learners further to articulate the theorem and to grapple some more with the relationship between the angle at the centre and at the circumference. As they were talking about this diagram, a number of issues came up for the learners and they raised them as questions, which the teacher responded to. Here is an extract from the extended exchange:

301 Gavin: Sir, couldn't B be a diameter as well? ${ }^{2}$

302 Teacher: Couldn't?

303 Gavin: ... B be a diameter?

304 Teacher: Can B be a diameter?

305 Learner: No, it's not going through the centre.

\footnotetext{
${ }^{2}$ It is not clear to the researcher which point the learner was referring to here.
} 
306 Teacher: It's not going through the centre of the circle, okay (Gavin nods). David?

307 David: Sir, can you say that the angle subtended from the diameter is always ninety degrees?

308 Teacher: Okay, David is just saying that the angle, which is subtended by the diameter is always ninety degrees. Can you see there, can you see this diameter with a line over there, it subtends one angle there, this diameter, subtends one angle there (he shows how the chord subtends the different angles) so what are we basically saying here now, it's not just arcs that subtends angles, but a chord can also subtend an angle. Let's look at that.

309 Learner: Are they always equal to ninety?

310 Teacher: He says it's always equal to ninety. Why are they always equal to ninety?

311 David: Because they'll always be one eighty.

312 Teacher: Because the diameter, the angle, in other words that is formed by the diameter, is always 180 . If that is always 180 then the angle at the circle like you guys rightly said will always be 90 .

313 Learners: Aah

314 Teacher: But can you see, we can see this BC as a chord, which is your diameter. So what we saying is the angle which is subtended by the diameter is always equal to ninety, is everybody getting that?

315 Learners: Yes.

316 Teacher: Where must that angle be, however? David, d'you mind being more specific?

317 David: It must be on the arc.

318 Teacher: It must be?

319 David: On the arc.

320 Teacher: Now you are saying that any angle subtended by the diameter is always equal to?

321 David: On the circumference

322 Teacher: The angle must be on the circumference of the circle okay

323 Nathan: (Inaudible)

324 Teacher: I don't understand what you're saying, just say it again.
325 Nathan: Sir you said it must be on the chord, Sir, but it is straight Sir, it's touching both sides (stretches out arms to indicate straight angle).

326 Teacher: Okay. No I fully agree with you Nathan, it must be the diameter, you are saying that it must be subtended by the diameter, in other words this time, this time it's the diameter that is opposite the angle, it's the diameter that determines the size of the angle, okay? Can you see that there, the same link those two points and the diameter?

327 Nathan: So if it was changed Sir, will the others still equal whatever?

328 Teacher: What do you mean it was changed?

329 Nathan: The diameter, if it was changed, say if it was seventy five or something.

In the above exchange of 29 turns there are 5 learner questions. The teacher dealt with the first question (line 301) relatively quickly by getting a response from another learner that satisfied Gavin. At this point, David's hand was up and the teacher moved on to his question (line 307). The teacher responded to David's question by revoicing it for the class - articulating it more clearly so that all could hear it and adding the weight of his voice, that it was an important question to consider (O'Connor \& Michaels, 1996). As the teacher did this, another learner repeated the question (line 309). The teacher asked David to justify the claim in his question, which he did, with reference to the angle at the centre being 180 degrees. Again, the teacher repeated David's point and then asked another question, which related to some of the difficulties the class had been having earlier. From lines 316 to line 322, the teacher used a traditional IRE sequence to get David to see that the angle should be on the circumference. Then Nathan came in with two questions (lines 325 and 327) which he did not articulate clearly and which the teacher spent some time trying to clarify.

Exchanges like this are both learner- and teacher-directed. They are learner-directed in that the learners' questions drive the dialogue and the teacher is willing to divert from his teaching agenda somewhat to listen to and work with learners' questions. They are teacher-directed in that the teacher is still in control; he decides to allow the learners to ask the questions and he chooses how to respond to them. In this case, the teacher had a number of ways of responding to the 
questions: (i) he revoiced them, so that others could contribute to answering them; (ii) he asked for justifications; (iii) he worked to clarify questions that were unclear; and (iv) he used the opportunities the questions presented to make some teaching points and reverted to traditional IRE mode to do so. The first three of these responses correspond to higher-level evaluations and uptake, where the teacher shows interest in the question, takes it seriously and makes it part of the lesson (Nystrand \& Gamoran, 1991).

The fourth response, using the learners' questions to make teaching points is characterized by a traditional IRE structure, although in this case there was no funnelling. The first three responses are characterized by what can be called a reverse IRE - learners initiating and the teacher responding. This reverse IRE is not a complete reversal, because the teacher still teaches. He does not respond to the learner questions with answers only, as they would to him. Rather he chooses from a range of teaching moves, which sometimes shift him back to a traditional IRE. Nevertheless, the interaction during the reversal is much more responsive and there is more real dialogue between teacher and learners.

So although this exchange interrupts the traditional IRE in some ways, it also maintains it. This kind of exchange goes beyond traditional question-and-answer exchanges in that there is no narrowing of the task demands, as in the previous example, and there is definitely a sense of a teacher in dialogue with his learners, while still teaching. The following example shows learners talking to each other.

\section{Example 3: Learner-learner dialogue}

This example comes from the same grade 11 classroom discussed in Example 1 where the teacher funnelled his questions. In this case, the teacher supported an extended dialogue between two learners. The learners were talking about what is similar in the graphs of $y=x^{2} ; y=(x+4)^{2}$ and $y$ $=(\mathrm{x}-3)^{2}$.

149 Mamokete $^{3}$ : Oh, they are similar in... why I am saying they are similar in the y-values, we don't have the value of $\mathrm{q}$ there, it shows that if it is not there, it is zero, that value of $\mathrm{q}$, that is why they are the same throughout.

\footnotetext{
${ }^{3}$ Much of the talk in this lesson was in Setswana. The videotapes were transcribed in the original Setswana and then translated into English.
}

150 Teacher: Questions, comments? Mapula?

151 Mapula: Which y-value, where is the $y$-value? For what? y-value of which point?

152 Mamokete: For the turning point.

153 Mapula: Only?

154 Mamokete: What do you mean?

155 Learners: (laugh)

156 Mapula: It means only they are similar. You say they are similar in yvalues, don't you?

157 Mamokete: Yes.

158 Mapula: So, I am asking that, you are implying that its y-value is zero?

159 Mamokete: Yes.

160 Mapula: For the turning point?

161 Mamokete: Yes.

162 Mapula: Oh, what about there, our yvalue is not the same.

163 Mamokete: The other y-value?

164 Mapula: For the other points (inaudible) on this graph, that lies on the graph, the one on the graph, are they not the same? (she is pointing at the sheet)

165 Mamokete: They are the same, these graphs move to left and right, so there is no way that they cannot be the same.

166 Mapula: Oh.

167 Teacher: Do you understand her question?

168 Mamokete: Yes.

169 Teacher: What is she saying?

170 Mamokete: She says I am implying that at the other points, besides the turning point, the y-value is not the same, and I said they are the same. (Aganang raises hand)

171 Teacher: Mm.

172 Aganang: But that other time you said that since there is no q, it means then that the y-value is zero, but on the other points. (she is pointing at the board)

173 Mamokete: (interrupts Aganang) We are talking about the turning point, I am talking about the turning point.

In the exchange Mapula was pushing Mamokete to be specific about which points she was claiming had the same $y$-values. Initially Mamokete was referring to the turning points only; she spoke about the $\mathrm{q}$ value being zero in all three graphs and in line 152 she explicitly said she was talking 
about the turning points. However, through Mapula's questioning, particularly in line 164, she seemed to shift her view, saying that since the graphs moved horizontally, all the y-values (of corresponding points) would stay the same. This indicates a shift in her thinking, made through the conversation. However, when Aganang challenged her by saying that she was contradicting an earlier point, it seemed that Mamokete might shift back to her earlier position. Such shifting of positions is characteristic of genuine dialogue and suggests that the learner is thinking through her ideas far more than a learner who tries to provide an answer that she thinks the teacher wants to hear. Through this interaction, the girls were exploring the nature of the graphs and their relationships to the equations. They took seriously the roles of asking and answering questions to clarify each other's thinking, and were taking up each other's ideas in ways that teachers rarely do (Nystrand et al, 1997).

We can raise the question as to whether the two girls, Mapula and Aganang, were asking authentic questions, or whether they actually knew the answers to their questions but were pointing out contradictions and pushing their classmate to clarify her own ideas. We can't know the definite answer to this, but from the questioners' confidence and persistence and the actual content of their questions (for example lines 153 and 162), it seems that they did have an idea of potential answers to their questions and were pushing Mamokete to think more deeply. Also, the learners had worked on the task in groups the previous day, and so would have thought through the ideas and had some confidence in their own positions. In this case they were most likely modelling the way their own teacher asks questions (Molefe, 2003). So while they were certainly evaluating Mamokete's ideas (see for example lines 153, 162, 172), their evaluations did not serve to narrow or funnel the task but allowed Mamokete to clarify her thinking and to disagree with them (lines 165, 170). Although the girls work in initiation-response turns and the exchange may look like an IRE in form, their questions and evaluations play a different role from those in the traditional IRE. So here we see an IRE in form but not in function; the interaction is closer to a real dialogue.

The teacher took only three turns in this exchange (lines 150, 167, 171), which is very unusual in mathematics classrooms. This teacher supported similar exchanges a number of times in his classroom. In this case his three turns did not make any substantial mathematical contributions but rather were directed at getting learners to talk and listen to each other. The first opened the floor for contributions, while the second and the third intervened to ensure that the learners were not miscommunicating. The teacher's third contribution supported Mamokete to repeat the point that she had learned through the conversation, which then allowed Aganang to come in, suggesting a contradiction with Mamokete's earlier position.

This example is probably closest to the notion of 'facilitator' promoted in the new South African curriculum documents. The teacher facilitated in this way a number of times during two weeks of lesson observations. At the same time, he also narrowed and funnelled his questions, as shown in the first example. This suggests that no teacher will consistently use one style of teaching and may vary between different approaches. It also raises the question of how the teacher worked in order to get the learners to be able to interact like this. This does not happen easily and requires a lot of work early in the year to establish the norms and ground rules for interacting in this way (Boaler \& Humphreys, 2005; Lampert, 2001; Staples, 2004).

The foregoing interaction is predominantly between two learners. The next example shows a number of learners interacting around a controversial mathematical point.

\section{Example 4: Whole-class dialogue}

This example comes from a grade 10 classroom where a learner had asked why $-2 \times 0$ gives 0 and not -0 , since a negative times a positive should give a negative. The teacher recognized this as an interesting question and allowed learners to discuss the issue:

152 Teacher: Eh, we can write negative zero, what d'you want to say Victor?

153 Victor: No, Sir, zero is neutral, Sir.

154 Teacher: Zero is neutral. What neutral? We are not driving a car here, ne?

155 Victor: Zero can be positive, zero can be negative, Sir.

156 Teacher: Hah? Is a zero positive or negative?

157 Learners: (mutter inaudibly) Both.

158 Teacher: Yes, Grant, let's listen to Grant. Come, come, let's listen.

159 Grant: Sir, on a number line you won't find a negative zero or positive zero. Its just gonna be zero because it's in between all those numbers. (inaudible)

160 Teacher: So is there a difference if I write negative zero or positive zero? 
161 Learners: No. it's the same.

162 Teacher: It's the same thing?

163 Learners: Yes.

164 Teacher: Then, why do we write it just as zero? Why don't I write negative?

165 Learner: Because zero it's....

166 Teacher: Yes, Fred.

167 Learner: Because zero, Sir, it's nothing, Sir.

168 Teacher: Nothing.

169 Fred: Yes.

170 Emily: Sir, zero is just like $\mathrm{x}$ because sometimes it's positive and sometimes it's negative.

171 Teacher: No. If I write $x$, if I write $x$, if I write $\mathrm{x}$ like this, is it positive $\mathrm{x}$, or negative $\mathrm{x}$ ?

172 Learners: Positive.

173 Teacher: So if I write zero like this is it positive zero or negative zero?

174 Learners: Positive, negative.

175 Teacher: Lebo?

176 Lebo: I ... positive.

177 Teacher: This is positive zero, Lebo?

178 Lebo: Ja, it is, because there's no sign.

179 Teacher: Positive zero.

180 Lebo: But, Sir, my question still remains.

181 Teacher: So, let's, let's write negative zero.

182 Learner: Ja.

183 Teacher: Must we write negative zero?

184 Learners: No.

185 Teacher: Why not man?

186 Lebo: Why, why?

187 Fred: No, zero, it's nothing Sir. You just give it a value....

188 Lebo: You can't say... I disagree with Fred, you can't say zero is nothing. What's the aim of writing it if it's nothing, Sir?

189 Emily: Zero, it's a zero, it's not a number (learners laughing). Serious, Sir. Sir, you said $\mathrm{x}$ can represent any number but zero you can see it's a nought sir.

190 Teacher: Ok, let's get finality here.

191 Lebo: If they say, if they say, zero it's nothing. Why did you, em, you give us an example like, zero times zero plus one. If zero it's nothing, why did you say zero times zero?
In the above extract of forty turns, five learners made contributions. All of these contributions were sensible and useful and many of them responded to and built on previous contributions. The learners were grappling with important mathematical ideas: is zero a number; what does the sign in front of a number indicate; and making links between their numerical and algebraic knowledge. They were also engaged in the discussion, because they found the issue interesting and had contributions to make.

The role of the teacher in this discussion is interesting. I argue elsewhere that allowing for such a conversation is an important move, even though it diverted the class from the main issue they were discussing (Brodie, 2007). The teacher clearly recognized the question as useful and thought it important to support a conversation around this. In contrast to the previous example, the teacher made many contributions to this conversation, almost every turn. Some of his contributions commented explicitly on the mathematics, for example in line 154, when he implied that they can't use the word neutral to talk about a number. In other cases he repeated learner contributions (lines 162, 168, 171, 177) in a "neutral" tone, allowing the learner to re-iterate their position. In others, he repeated the question under discussion $(156,160,181,185)$. In lines 181 and 185 , the teacher actually suggested that they can write negative zero and, together with Lebo (line 186), challenged the other learners as to why they were claiming that they could not. Although the teacher remained neutral in some of his moves, in others he suggested a position, not necessarily his own position but one that would provoke and challenge the learners. He asked questions to which he knew the answers, but these questions served to elicit genuine learner thinking. None of his contributions narrowed the task, he did not funnel learners to an answer, and he took their ideas seriously, both Lebo's, whose question started the discussion, and the ideas of others who contributed (except possibly for Victor's). So even though this teacher takes almost half the turns in the discussion, learners get to express their views, hear others and build on each other's ideas.

\section{Discussion and conclusions}

In this paper I have built on existing literature which argues that merely engaging in questionand-answer exchanges does not necessarily allow for genuine learner participation in the lesson, nor takes learners' mathematical thinking seriously. To illustrate this point, I used an example (Example 1) of a teacher funnelling a learner through narrowing 


\section{Karin Brodie}

his questions, even when the learner was making a valid mathematical argument. My main argument is that there are other ways of interacting that support more genuine participation and thinking. I gave three examples (Examples 2, 3 and 4) of such interaction that I have encountered in South African classrooms - and I believe that there are more waiting to be described. These three examples have a number of differences and similarities, which I will discuss below.

My analysis of these examples contributes some interesting insights to the already existing literature on classroom interactions. First it shows that the IRE exchange structure can be shifted, as in Examples 2 and 3. The shift happened in different ways in the two examples. In Example 2, the IRE was partially reversed and the teacher had to respond to a number of learner questions. In Example 3, learners interacted in initiationresponse turns, and their evaluations worked differently from those of a teacher, serving to push one of their peers to think more deeply. So this exchange was more like a dialogue. Example 4 shows that the IRE does not need to shift in order for dialogue to take place. In this case the teacher contributed in almost every other turn and many of his comments were evaluative or could be read as such by the learners, but he still managed to support a conversation.

Another important insight that emerges from this analysis is that even when teachers manage to shift the IRE structure, they are unlikely to be able to do this all of the time. In Example 2, we see how in responding to learners' questions, the teacher switched into an IRE mode in order to make some teaching points, and then switched back to a more responsive interaction pattern. It is likely that such switching between modes is appropriate as a teaching technique, both in terms of supporting participation and learning, and also in terms of expectations for teacher change. It is a far less daunting task to change some aspects of one's practices and interaction patterns, rather than having to let go of everything. The first teacher is interesting in this regard because he is the teacher in the study who managed most to support learners to question each other. This teacher had been working on this practice for some years before I visited his classroom and was very successful in doing it. At the same time he also funnelled and narrowed his questions (as did the other two teachers). This adds to the point that teachers may be able to make some changes at some times in their teaching, but at other times may revert to more conventional methods. The processes of changing teaching practice are slow and uneven (see also Slonimsky \& Brodie, 2007).

This analysis also addresses some issues in relation to the kinds of questions that support learner participation. Nystrand et al. (1997) argue that such questions should be authentic. However, in these three cases, we see a mix of authentic and non-authentic questions. In Example 2, the learners' questions were authentic, but the teacher's were not. In Example 3, the learners' questions may or may not have been authentic. In Example 4, there were very few authentic questions from the teacher, although Lebo's question that started the discussion was authentic. And so it seems that while authentic questions are part of creating genuine dialogue, they may not be sufficient, on their own. It may be the case that some authentic questions are necessary but that switching between different kinds of questions is the most helpful in supporting genuine participation.

What the three examples of dialogue have in common - and what is different from the first case - is that the teachers did not narrow the task demands and did not funnel learners towards an answer. It may be that the insights of Bauersfeld (1980) and Stein et al. (2000) are key here, and that to increase participation and mathematical thinking, teachers need to learn to maintain the task demands. This is not an easy task as Stein et al. (1996; 2000) show, because time constraints and teachers' genuine desire to help learners serve to lower task demands. A case study of curriculum implementation in grade 10 in 2006 shows that a teacher who did select higher level tasks, as required by the new curriculum, was not able to maintain the level of the tasks during classroom interaction, and his interaction patterns served to narrow and funnel the tasks (Jina, 2007; Modau, 2007). This has important implications for teacher development. It might be that focusing on both the goal of selecting higher order tasks and working to maintain the level of the tasks in interaction with learners is a useful first step, which will allow teachers to focus on what to do, rather than on what not to do.

Finally, this study raises an important question: how did these three teachers manage to achieve genuine participation, at least for some of the time, in their lessons? This question is beyond the scope of this paper, and has been addressed somewhat by others (Boaler \& Humphreys, 2005; Chazan, 2000; Lampert, 2001; Staples, 2004), although in nonSouth African contexts. These studies describe how teachers do manage to create classroom 
cultures that support participation and learning. We need to do similar research to see how to achieve participation in the South African context. We know that such classrooms are not often seen - in South Africa, the rest of Africa, and beyond (Brodie, Lelliott, \& Davis, 2002; Chisholm, Volmink, Ndhlovu, Potenza, Mahomed, Muller, et al, 2000; Cuban, 1993; Sugrue, 1997; Tabulawa, 1998; Tatto, 1999). However, it is my view that when genuine participatory classrooms are created they can be liberating and empowering for both teacher and learners, as the above examples show. Developing such classrooms is a goal that is well worth working towards.

\section{References}

Bauersfeld, H. (1980). Hidden dimensions in the so-called reality of a mathematics classroom. Educational Studies in Mathematics, 11, 23-41.

Boaler, J. \& Brodie, K. (2004). The importance, nature and impact of teacher questions. In D.E. McDougall \& J.A. Ross (Eds.), Proceedings of the 26th annual meeting of the North American chapter of the International Group for the Psychology of Mathematics Education (Vol. 2, pp 773-781). Toronto: Ontario Institute of Studies in Education/University of Toronto.

Boaler, J. \& Humphreys, C. (2005). Connecting mathematical ideas: middle school cases of teaching and learning. Portsmouth, $\mathrm{NH}$ : Heinemann.

Brodie, K. (2003). Being a facilitator and a mediator in mathematics classrooms: a multidimensional task. In S. Jaffer \& L. Burgess (Eds.), Proceedings of the 9th national congress of the Association for Mathematics Education of South Africa (pp 135-146). Cape Town: University of Cape Town.

Brodie, K. (2007). Teaching with conversations: beginnings and endings. For the Learning of Mathematics, 27(1), 17-23.

Brodie, K., Lelliott, T. \& Davis, H. (2002). Forms and substance in learner-centred teaching: teachers' take-up from an in-service programme in South Africa. Teaching and Teacher Education, 18, 541-559.

Chazan, D. (2000). Beyond formulas in mathematics and teaching: dynamics of the high school algebra classroom. New York: Teachers' College Press.

Chazan, D. \& Ball, D.L. (1999). Beyond being told not to tell. For the Learning of Mathematics, 19(2), 2-10.
Chisholm, L., Volmink, J., Ndhlovu, T., Potenza, E., Mahomed, H., Muller, J., et al. (2000). A South African curriculum for the twenty first century. Report of the review committee on Curriculum 2005. Pretoria: Department of Education.

Cuban, L. (1993). How teachers taught: Constancy and change in American classrooms. New York: Teachers' College Press.

Davis, B. (1997). Listening for differences: an evolving conception of mathematics teaching. Journal for Research in Mathematics Education, 28(3), 355-376.

Edwards, D. \& Mercer, N. (1987). Common knowledge: the growth of understanding in the classroom. London: Routledge.

Hiebert, J. \& Wearne, D. (1993). Instructional tasks, classroom discourse, and students' learning in second-grade arithmetic. American Educational Research Journal, 30(2), 393-425.

Jina, Z. (2007). Teacher questioning and curriculum change. Unpublished Masters Research Report, University of the Witwatersrand, Johannesburg.

Lampert, M. (2001). Teaching problems and the problems of teaching. New Haven: Yale University Press.

Lobato, J., Clarke, D. \& Ellis, A.B. (2005). Initiating and eliciting in teaching: a reformulation of telling. Journal for Research in Mathematics Education, 36(2), 101-136.

Mehan, H. (1979). Learning lessons: social organisation in the classroom. Cambridge, MA: Harvard University Press.

Modau, A.S. (2007). A teacher's selection and use of tasks in the old and new curriculum. Unpublished Masters Research Report, University of the Witwatersrand, Johannesburg.

Molefe, N. (2003). Mathematical reasoning. Unpublished Honours Research Report, University of the Witwatersrand, Johannesburg.

Nystrand, M. \& Gamoran, A. (1991). Student engagement: when recitation becomes conversation. In H.C. Waxman \& H.J. Walberg (Eds.), Effective teaching: current research (pp 257276). Berkeley, CA: McCutchan Publishing Corporation.

Nystrand, M., Gamoran, A., Kachur, R. \& Prendergast, C. (1997). Opening dialogue. New York: Teachers College Press.

O'Connor, M.C. \& Michaels, S. (1996). Shifting participant frameworks: orchestrating thinking practices in group discussion. In D. Hicks (Ed.), Discourse, learning and schooling (pp 63-103). New York: Cambridge University Press. 


\section{Karin Brodie}

Sinclair, J.M. \& Coulthard, R.M. (1975). Towards an analysis of discourse: The English used by teachers and pupils. London: Oxford University Press.

Slonimsky, L. \& Brodie, K. (2007). Teacher learning: development in and with social context. South African Review of Education, 12(1) 45-62.

Staples, M. (2004). Developing a community of collaborative learners: Reconfiguring roles, relationships, and practices in a high school mathematics classroom. Unpublished $\mathrm{PhD}$ thesis, Stanford University, California.

Stein, M.K., Grover, B.W. \& Henningsen, M.A. (1996). Building student capacity for mathematical thinking and reasoning: an analysis of mathematical tasks used in reform classrooms. American Educational Research Journal, 33(2), 455-488.
Stein, M.K., Smith, M.S., Henningsen, M.A. \& Silver, E.A. (2000). Implementing standardsbased mathematics instruction: a casebook for professional development. New York: Teachers College Press.

Sugrue, C. (1997). Complexities of teaching: childcentred perspectives. London: Falmer Press.

Tabulawa, R. (1998). Teachers' perspectives on classroom practice in Botswana: implications for pedagogical change. International Journal of Qualitative Studies in Education, 11(2), 249268.

Tatto, M. (1999). Improving teacher education in rural Mexico: the challenges and tensions of constructivist reform. Teaching and Teacher Education, 15, 15-35.

Wells, G. (1999). Dialogic inquiry: toward a sociocultural practice and theory of education. Cambridge: Cambridge University Press.

"One of the big misapprehensions about mathematics that we perpetrate in our classrooms is that the teacher always seems to know the answer to any problem that is discussed. This gives students the idea that there is a book somewhere with all the right answers to all of the interesting questions, and that teachers know those answers. And if one could get hold of the book, one would have everything settled. That's so unlike the true nature of mathematics." 